\title{
The commodity systems of Brassica rapa L. subsp. chinensis and Solanum retroflexum Dun. in Vhembe, Limpopo Province, South Africa ${ }^{\#}$
}

\author{
W van Averbeke*, TE Tshikalange and KA Juma \\ Centre for Organic and Smallholder Agriculture, Department of Crop Sciences, Tshwane University of Technology, \\ Private Bag X680, Pretoria 0001, South Africa
}

\begin{abstract}
Using farmer surveys the smallholder commodity systems of Brassica rapa L. subsp. chinensis and Solanum retroflexum Dun. in Vhembe District, Limpopo Province, South Africa were described and analysed. Production, transaction and consumption of the two vegetables were deeply embedded in the food, trade and farming systems of local people. The cultivation systems, which appeared effective, were developed by borrowing elements from the systems of other crops to which new knowledge specific to $B$. chinensis and $S$. retroflexum were added. Several elements of the production systems that could benefit from scientific enquiry were identified. These included genetic improvement and the optimisation of planting density and nutrient supply.
\end{abstract}

Keywords: Smallholder commodity systems, filière, African leafy vegetables; Chinese cabbage, nightshade

\section{Introduction}

In this study, the smallholder commodity systems of Brassica rapa L. subsp. chinensis and Solanum retroflexum Dun. are described and analysed. In South Africa, these two vegetables are exclusively produced and consumed by African people.

B. rapa subsp. chinensis refers to non-heading types of Chinese cabbage (Opeňa et al., 1988), an annual, flowering vegetable with dark green leaves supported by light green to white petioles that form a rosette (Hill, 1990). Chinese cabbage has a short growing season. From sowing to the end of the vegetative stage takes about six weeks for early maturing cultivars and 11 weeks for late maturing cultivars (Rubatzky andYamaguchi, 1997; Hong$\mathrm{Fu}, 1988$ ). Depending on the cultivar, the plants reach a height of $15 \mathrm{~cm}$ to $30 \mathrm{~cm}$ at the end of the vegetative stage. The progenitor form of Chinese cabbage, Brassica campestris, is believed to have evolved in the Mediterranean from where it was introduced to China more than 2000 years ago and differentiated into the various subspecies (Opeña et al., 1988). The crop probably found its way from Asia into Africa as a result of trade between these two continents.

Solanum retroflexu Dun. forms part of the $S$. nigrum complex of species and is indigenous to South Africa (Grabandt, 1985; Edmonds and Chweya, 1997). Other species in the Solanum nigrum complex that are commonly found in Africa include $S$. gracile, $S$. villosum, $S$. nodiflo-

\footnotetext{
\# Revised version. Originally presented at the International Symposium on the Nutritional Value and Water Use of Indigenous Crops for Improved Livelihoods held on 19 and 20 September 2006 at the University of Pretoria in Pretoria, South Africa

* To whom all correspondence should be addressed.

酒 +2712 382 5777; fax: +2712 382 5869; e-mail: vanaverbekew@tut.ac.za
}

rum (S. americanum), S. nigrum and S. scabrum (Edmonds and Chweya, 1997). S. retroflexum is an annual branching herb that grows up to $75 \mathrm{~cm}$ in height, has alternate, heavily veined leaves with small hairs on both sides, white flowers with a yellow centre and green berries that turn dark purple when ripe (Grabandt, 1985; Schippers, 2002).

Relative to white cabbage (B. oleracea L. var. capitata), which is arguably the most commonly produced and consumed leafy vegetable among black people in South Africa, the two crops studied here are richer in nutrients per unit fresh mass (Table 1). This makes them potentially suitable elements for inclusion in food-based approaches aimed at combating hidden hunger, which is an important type of under-nutrition among poor rural people in South Africa.

\begin{tabular}{|c|c|c|c|c|}
\hline \multicolumn{5}{|c|}{$\begin{array}{c}\text { TABLE } 1 \\
\text { Calcium, iron and Beta-carotene content of } 100 \mathrm{~g} \text { fresh edible portion of } \\
\text { Brassica oleracea L. var. capitata, Brassica rapa L. subsp. chinensis and } \\
\text { Solanum nigrum (adapted from Opeňa et al., 1988; Edmonds \& Chweya, 1997) }\end{array}$} \\
\hline \multirow[t]{2}{*}{ Scientific name } & \multirow[t]{2}{*}{\begin{tabular}{|l|} 
Common Eng- \\
lish name
\end{tabular}} & Calcium & Iron & $\begin{array}{c}\text { Beta-carotene } \\
\text { equivalent }\end{array}$ \\
\hline & & (g) & (mg) & $(\mu \mathrm{g})$ \\
\hline Brassica. oleracea L. var. capitata & White cabbage & 55 & 0.8 & 280 \\
\hline Brassica rapa L. subsp. chinensis & $\begin{array}{l}\text { Non-heading } \\
\text { Chinese cabbage }\end{array}$ & 102 & 2.6 & 2305 \\
\hline Solanum nigrum L. & $\begin{array}{l}\text { Black night- } \\
\text { shade }\end{array}$ & 266 & 2.6 & 6650 \\
\hline
\end{tabular}

A commodity system or chain, called filière in the French language, involves many activities, including production, collection, up-stream storage, transformation, down-stream storage, redistribution and consumption. The filière approach, illustrated in Fig. 1, is used as a framework to investigate the way in which particular agricultural commodities are produced, stored, transformed, transacted and consumed in a locality or region (Leplaideur, 1994; Moustier et al., 1997).

Van Averbeke and Khosa (2004) developed the Triple-A framework, illustrated in Fig. 2, to guide the study of small- 

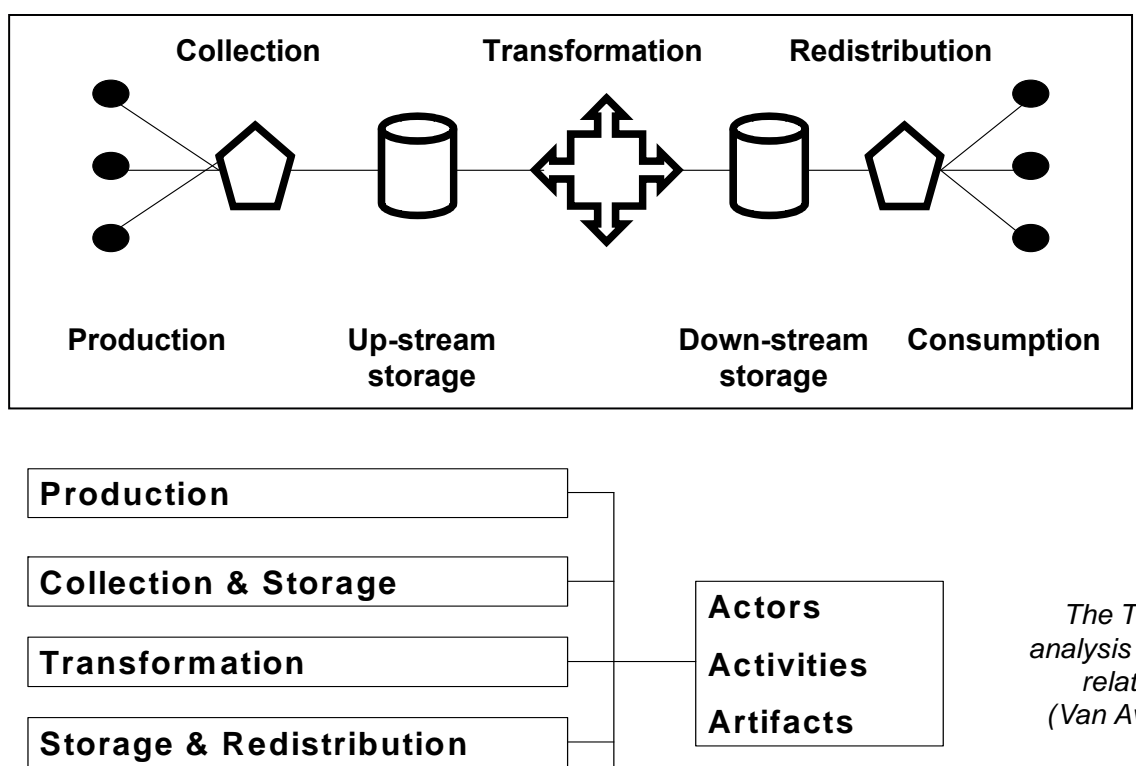

Figure 1

Analytical framework used in filière studies (after Leplaideur, 1994)

\section{Consumption}

holder commodity chains or systems.

In the triple-A framework actors refer to the people or agencies involved in smallholder commodity chains, activities to what they do and artefacts to what they use in the conduct of their activities. These three elements constitute the core of the indigenous knowledge system that is applied in smallholder commodity chains. Indigenous knowledge resides within the actors. Through experimentation actors develop, adopt or adapt material and social technology to suit their circumstances. Technology can be called an artefact because it is a human creation. Usually artefacts are material objects, but for the purpose of the study of smallholder commodity chains the concept can be expanded to include both tangible and intangible creations of people. These can include, for example, different landraces of a particular crop, equipment, materials and techniques used in the cultivation, harvesting or processing of the crop and the social arrangements that characterise transactions.

The main focus of the analysis of the two commodity systems was on the cultivation of the two vegetables. Analysis of the technical content of the existing cultivation system of a crop is important when seeking to contribute to its development through agronomic research. Existing systems contain elements of best-practice, which farmers have discovered and refined through observation and experimentation over many years.

\section{Materials and methods}

Using the Triple-A framework as a guide, empirical data were collected by means of farmer surveys at selected sites in the Vhembe District. Vhembe is the most northern district of the Limpopo Province and borders Zimbabwe. This District is regarded as the origin of cultivation of $B$. rapa subsp. chinensis and $S$. retroflexum in South Africa. Vhembe forms part of the summer rainfall region and since both crops are grown during winter they are produced under irrigation. For this reason the surveys were conducted on smallholder irrigation schemes where the two crops are being produced. All of these smallholder projects were canal irrigation schemes with plot sizes that ranged between 0.6 ha and 1.3 ha. Face-to-face interviews guided by a checklist of issues were used to collect the data and where pos- sible participants were requested to demonstrate their practices. This enabled the collection of quantitative data on inter alia fertiliser application rates and plant spacing, using a portable scale and a measuring tape to make the measurements. Purposive sampling (Strydom, 2005), which is a non-probability sampling method, was used to compose the sample of participants. This involved the identification of farmers who actively produced the crops under consideration, using the resident extension officers and other farmers as sources of referral. Forty irrigation farmers participated in the $B$. chinensis commodity system survey,

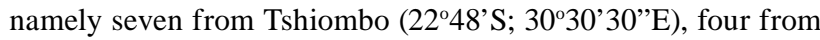

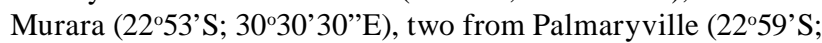

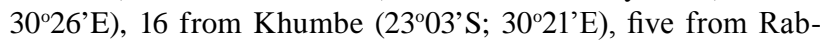

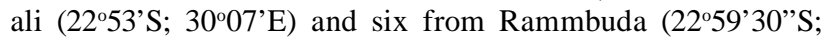
$\left.30^{\circ} 25^{\prime} 30^{\prime \prime} \mathrm{E}\right)$. In total 50 irrigation farmers participated in the $S$. retroflexum commodity system survey, namely 30 at Dzindi (30 $23^{\circ}$ 'S; $\left.23^{\circ} 01^{\prime} \mathrm{E}\right), 9$ at Rabali and 11 at Khumbe.

The data were analysed qualitatively. This consisted of writing up each interview in full, followed by analysing the information in these texts in accordance with the pre-determined themes contained in the checklist. Analysis of the different farmer practices paid particular attention to the degree of diversity or variability. When a particular practice showed limited variability among farmers, this was interpreted as an indication of consensus among participants that this particular way of doing things consistently produced the best results. Conversely, when a practice was subject to wide diversity, this was interpreted as evidence of uncertainty among farmers of what worked best. Where information was of a quantitative nature, the data were converted to a standardised format. This enabled the determination of measures of their central tendency and spread using the Descriptive Statistics routine of the Data Analysis routine contained in the Tools routine of MS Office Excel version 2003.

\section{Results and discussion}

\section{Origin, diversity and reproduction}

Participants in the survey identified 11 different landraces of B. chinensis, all of which had been given local names. The 
landraces dabadaba and lidzhainthi were by far the most commonly grown, followed by tshikete and mutshaina wa u navha. The other seven landraces were produced by a few farmers only. Participants named Zimbabwe as the origin of 10 of the 11 landraces that were identified. They said that petty traders from Zimbabwe, who marketed bambara groundnuts in Vhembe, had been distributing the seed of the different landraces of Chinese cabbage. Dabadaba was the only exception. Some participants claimed that this landrace was transferred from the wild by local people, whilst others believed that it also entered Vhembe from Zimbabwe. Participants identified the village of Maraxwe, near the Tshiombo and Rammbuda Irrigation Schemes, as the centre of indigenous knowledge of Chinese cabbage in Vhembe. Indications are that cultivation of this crop commenced during the 1940s. Once farmers had acquired seed of a particular landrace they sustained its reproduction. Utilisation of the different landraces was spread among farmers through seed exchanges. Efforts by farmers to improve the crop were rare and limited to selecting seed from plants that produced exceptionally large numbers of leaves, which was done by three of the 40 participants. The others left their entire stand to mature and dry on the land and then collected the dry plants for threshing and seed collection. Threshed seed was stored in different types of containers, including glass bottles, plastic containers, paper, plastic, woven polypropylene bags, pieces of cloth and dzikhali, which are traditional clay pots that are covered with a clay lid. Seeds stored in dzikhali were reported to maintain their viability the longest, up to three years, whilst seed stored in other containers only lasted up to two years. The extent to which this is true was not verified.

Before $S$. retroflexum was taken into cultivation, people in Vhembe harvested the plant from the wild for use as a vegetable. Respondents reported that in the wild, the plant was typically found under large trees in mountain forests. Birds were identified as the most likely distributors of $S$. retroflexum in the wild, because they consumed the berries and probably excreted the seeds whilst resting on trees. The harvesting of $S$. nigrum species from the wild for use as a leafy vegetable is not limited to the Vhembe District. Similar use of S. scabrum has been reported in the KwaZulu-Natal and Eastern Cape Provinces of South Africa (Juma, 2006). However, cultivation of S. nigrum species in South Africa is at this stage restricted to the Vhembe District, where reportedly it commenced during the 1960s at Dzindi, the centre of indigenous knowledge of this crop (Juma, 2006).

\section{Cultivation practices}

The seed of $B$. chinensis is 1.5 to $2 \mathrm{~mm}$ in size and fairly dense, making it possible to practise direct seeding, which was done by $33 \%$ of participants. When using direct seeding farmers opened a shallow planting furrow of about 2 to $3 \mathrm{~cm}$ deep using a hand hoe, sprinkled the seed in the furrow, covered the seed with about 1 to $2 \mathrm{~cm}$ of soil, and then irrigated the soil. Once the plants had emerged and had 3 to 5 true leaves, they were thinned out to achieve the desired stand. Often the plants that were pulled out during thinning were used to plant additional land to Chinese cabbage. Farmers who planted their plots using transplants produced these in specially prepared seed beds. These consisted of small areas in which the soil was worked to a fine tilth using a garden fork or a hand hoe. After incorporating fertilisers into the soil of the seedbed farmers used a stick or finger to open shallow (about $10 \mathrm{~mm}$ deep) and narrow (about 15 to $20 \mathrm{~mm}$ wide) furrows spaced 3 to $5 \mathrm{~cm}$ apart. In these furrows they sprinkled the seed, which was then covered with a thin layer of about 5 to $7 \mathrm{~mm}$ soil. Watering cans or perforated buckets were used to irrigate the soil of the seedbed, and this was done every second day or more frequently. Seedlings typically emerged 2 to $7 \mathrm{~d}$ after sowing and were transplanted 3 to 6 weeks after sowing, when they had reached the $3^{\text {rd }}$ to $6^{\text {th }}$ leaf stage. When the seedlings were ready for transplanting, the seedbed was first watered thoroughly and then the transplants were pulled out from the seed bed by hand or dug out using a flat stick. Before being planted to the crop, the irrigation plot was ploughed, disked and ridged using mechanical means and then watered. Planting of seedlings was done by placing the roots of the transplants in shallow planting holes of about $3 \mathrm{~cm}$ deep, made by means of a round stick, followed by covering the roots with soil. The final planting density typically ranged between 4 and 8 plants $\cdot \mathrm{m}^{-2}$. Most respondents planted Chinese cabbage during April and May. They pointed out that earlier planting had the advantage of superior market conditions, but the disadvantage that it increased the incidence of pests. All participants applied fertilisers to increase the growth and yield of the Chinese cabbage plants. Farmers mostly used chemical fertilisers super-phosphate $(10.5 \% \mathrm{P})$, limestone ammonium nitrate (LAN $28 \% \mathrm{~N}$ ), or urea $(46 \% \mathrm{~N})$, or the fertiliser mixtures 2:3:4 (30) and 2:3:2 (22) to supply nutrients to the crop, but some applied organic fertilisers, mostly poultry manure. Irrespective of the type of fertiliser used, farmers employed a similar nutrient supply strategy, which consisted of the application of organic manure or a chemical fertiliser mixture at planting, followed by one or more topdressings with a nitrogenous fertiliser, most often LAN. Farmers employed a diversity of methods to apply fertilisers, including broadcast, band and spot application. The rates at which $\mathrm{N}, \mathrm{P}$ and $\mathrm{K}$ were applied also varied widely. Application rates of $\mathrm{N}$ ranged from $134 \mathrm{~kg} \mathrm{~N} \cdot \mathrm{ha}^{-1}$ to $545 \mathrm{~kg} \mathrm{~N} \cdot \mathrm{ha}^{-1}$ with a mean of $229 \mathrm{~kg} \mathrm{~N} \cdot \mathrm{ha}^{-1}$ and a median of $209 \mathrm{~kg} \mathrm{~N} \cdot \mathrm{ha}^{-1}$. Application rates of P ranged from $44 \mathrm{~kg} \mathrm{~N} \cdot \mathrm{ha}^{-1}$ to $277 \mathrm{~kg}$ P·ha ${ }^{-1}$ with a mean of 128 $\mathrm{kg} \mathrm{P} \cdot \mathrm{ha}^{-1}$ and a median of $119 \mathrm{~kg} \mathrm{P} \cdot \mathrm{ha}^{-1}$. Application rates of K ranged from $35 \mathrm{~kg} \mathrm{~K} \cdot \mathrm{ha}^{-1}$ to $207 \mathrm{~kg} \mathrm{~K} \cdot \mathrm{ha}^{-1}$ with a mean of $104 \mathrm{~kg}$ $\mathrm{K} \cdot \mathrm{ha} \mathrm{C}^{-1}$ and a median of $91 \mathrm{~kg} \mathrm{~K} \cdot \mathrm{ha}^{-1}$. On all the schemes included in the study, water was applied by means of short furrow irrigation (De Lange, 1994). Farmers pointed out that for optimum production the crop needed two or three irrigation per week, but in many instances the frequency of irrigation was limited to once per week because of the institutional arrangements governing access to water limited farmers to this particular irrigation frequency(Letsoalo and Van Averbeke, 2006). Crop protection was by chemical means. Respondents listed Bagrada bugs (Bagrada hilaris), cutworms (Agrotis segetum), cabbage aphids (Brevicoryne brassicae), spider mites (Tetranchus spp.), small red ants, birds and locusts as the main pests of Chinese cabbage. Commonly used chemicals for the control of insect pests were Metasystox (oxydemeton-methyl), Tamaron (methamidophos) and Cymbush (cypermethrin). Weeds were controlled by hand hoeing or by pulling out the weeds. During the growing season 2 to 8 weed control operations were performed.

$S$. retroflexum was grown from seed and reproduction was entirely maintained by local farmers. All farmers followed the same procedure to harvest the seed. The ripe fruit of the crop was collected, soaked in a container filled with water and then squeezed by hand whilst still in the water to separate the seed from the rest of the fruit. Decanting the supernatant and refilling the bucket with fresh water was sustained until the water remained clear. After the final decant, the seed which is denser than water was transferred onto plastic sheets or discarded polypropylene grain bags to dry. Once dry, the seed was stored in dry pieces of cloth or in sealed containers made from 
glass or plastic. Farmers pointed out that all of these storage methods ensured that the seed remained viable for at least two years. Seed selection, being one of the ways to increase production, was not given much attention by farmers. Only two of the 30 respondents at Dzindi selected specific plants for seed. One collected large fruit from plants with broad leaves, whilst the other set aside a group of plants specifically for seed production and did not harvest the shoots of these plants. Being small $(0.5$ to $1.5 \mathrm{~mm})$, the seed of $S$. retroflexum is not well suited for direct seeding, explaining why all respondents made use of transplants. These were produced in exactly the same way as described for $B$. chinensis. The duration of germination and emergence varied widely, ranging between five and $28 \mathrm{~d}$. According to Schippers (2002), the duration of germination of $S$. nigrum species is determined by the degree to which sugars and germination inhibitors present in the fruit have been removed from the seed. Transplanting of the seedlings was done 3 to 4 weeks after emergence. Farmers considered colour and degree of development of the seedlings when deciding on when to transplant. Generally, seedlings were considered ready for transplanting when their colour had turned from pale-green to deep green and when they had developed about 5 to 6 true leaves. To remove the transplants from the seedbed the seedlings were carefully uprooted. Soil attached to the roots of the seedlings was washed off. Farmers claimed that this enhanced root development of the seedlings. The seedlings were placed in holes of about 3 to $5 \mathrm{~cm}$ deep, which were drilled in the soil using a stick or forefinger. A single seedling was placed in each hole and then the soil around the roots was pressed down to ensure good contact between roots and soil. Whilst the majority of farmers practiced single row planting, some planted in double rows, which reportedly was done to suppress weed competition. The spacing between the plants varied widely among producers. Inter-row spacing ranged between $0.32 \mathrm{~m}$ to $0.90 \mathrm{~m}$ with a mean of $0.75 \mathrm{~m}$ and intra-row spacing from 0.12 to $0.60 \mathrm{~m}$ with a mean of $0.29 \mathrm{~m}$. Planting density varied widely, ranging between 1.9 plants $\cdot \mathrm{m}^{-2}$ and 26.0 plants $\cdot \mathrm{m}^{-2}$, with a mean of 6.3 plants $\mathrm{m}^{-2}$. The majority of respondents (55\%) used a planting density ranging between 3 and 5 plants $\cdot \mathrm{m}^{-2}$. Farmers employing planting densities in excess of 9 plants $\cdot \mathrm{m}^{-2}$ (19\%) all achieved these by using a double-row or tram-line planting pattern. The majority of farmers (98\%) used chemical fertilisers, but 36\% also applied organic fertilisers. Only one respondent applied organic fertilisers only. The nutrient supply strategy used by $S$. retroflexum producers was the same as that described for Chinese cabbage and the methods of applying fertilisers displayed the same type of diversity. Application rates ranged from 22 $\mathrm{kg} \mathrm{N} \cdot \mathrm{ha}^{-1}$ to $547 \mathrm{~kg} \mathrm{~N} \cdot \mathrm{ha}^{-1}$, with a mean of $208 \mathrm{~kg} \mathrm{~N} \cdot \mathrm{ha}^{-1}$ and a median of $185 \mathrm{~kg} \mathrm{~N} \cdot \mathrm{ha}^{-1}$. Phosphorus application rates used by S. retroflexum cultivators ranged from $6 \mathrm{~kg} \mathrm{P} \mathrm{ha}^{-1}$ to $295 \mathrm{~kg} \mathrm{P} \mathrm{ha}^{-1}$, with a mean of $51 \mathrm{~kg} P \cdot \mathrm{ha}^{-1}$ and a median of $42 \mathrm{~kg} P \cdot \mathrm{ha}^{-1}$. The

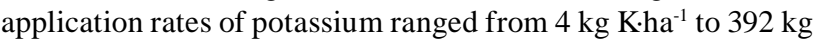

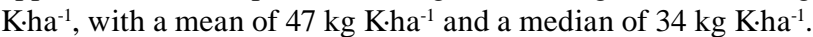
In all three schemes farmers were institutionally restricted to a single irrigation per week. Generally, respondents identified lack of water for irrigation as a constraint in the cultivation of $S$. retroflexum, suggesting that irrigation frequencies higher than once per week are needed for optimum growth of the crop.

\section{Harvest, marketing, processing and use}

The $5^{\text {th }}$ true leaf of Chinese cabbage was the first that was considered suitable for harvest and consumption. This particular leaf was harvested when the plants had reached the 8-leaf stage.
Typically, the $5^{\text {th }}$ leaf has a length of about $25 \mathrm{~cm}$ and a width of about $15 \mathrm{~cm}$. Farmers regarded the first four leaves to be too small to be marketable and many farmers pulled the first four leaves off the plant and discarded them when harvesting the $5^{\text {th }}$ leaf, because they believed that this stimulated growth. About one week after harvesting the $5^{\text {th }}$ leaf, subsequent leaves were harvested. The number of marketable leaves produced by Chinese cabbage depends on the landrace and the time of planting. The dabadaba landrace typically produces between 10 and 16 leaves, of which 6 to 12 leaves are large enough to be marketable. Harvesting the leaves of a plant continues until the peduncle has elongated and the first flowers open. Marketing of the crop is mainly done by petty traders who visit the irrigation schemes to purchase vegetables for sale on the streets of local towns. Small quantities are also sold by farmers to people in the villages surrounding the Schemes. Since 2005, supermarkets in the towns of Vhembe retail $B$. chinensis but none of the farmers covered by the survey used this particular channel to market the crop. About one in 10 farmers processes Chinese cabbage to avoid losses when part of the produce failed to find a market, which affected the June and July plantings in particular. Fresh Chinese cabbage leaves, to which cut-up tomatoes are added, are boiled until soft, squeezed by hand into small balls of about 2 to $4 \mathrm{~cm}$ in diameter, pressed down on a zinc roof sheet to yield a patty shape, and left to sun-dry. The dry patties are stored in plastic containers and consumed or sold during summer, when fresh B. chinensis is not available. Another preservation method involves the storing of blanched leaves without adding spices in a container in a freezer. Stored in this way the vegetable is said to retain its colour and taste for up to a year. Both fresh and processed leaves are used to prepare a relish to accompany maize porridge. There are two main ways of preparing the relish. One way is to stew Chinese cabbage leaves in a little water to which salt, tomato and cooking oil were added to improve the taste. The other involves the addition of peanut meal, resulting in a relish called dovhi. The flowers of the dabadaba landrace and the leaves attached to its peduncle are also used as a medicine to treat high blood pressure.

S. retroflexum is harvested for the first time about four to eight weeks after transplanting. This involves the cutting off the top branches of the plant, whilst leaving two or three branches at the base of plant. The majority of farmers commence harvesting when the branches of the plants have spread sufficiently to cover the ridges separating the irrigation furrows. They harvest the crop for the second time when the shoots have re-grown sufficiently, which usually occurs about 2 to 3 weeks after the first harvest. Harvesting ends when the crop starts to produce narrow, thin leaves, because these are no longer marketable. Fruit formation is also used as an indicator that it is time to stop the harvesting of shoots, because fruit formation is said to adversely affect the quality of the leaves, turning them sour and leathery. No evidence of processing of leaves was found. As with Chinese cabbage, petty traders controll the $S$. retroflexum market, but since 2005 the crop has also been on offer on the shelves of local stores that form part of a major national supermarket chain, being supplied daily and directly by selected farmers who owned trucks and specialised in the production of this crop. This development is a clear indication that the $S$. retroflexum commodity system is expanding in Vhembe. In the study area, leaves and young shoots of $S$. retroflexum are cooked and used as a relish. These plant parts are first separated from the main stems and then boiled in water. Sunflower oil, tomatoes and salt are added to enhance flavour. During cooking the first boiling water is discarded to reduce bitterness. 


\section{Conclusions}

The description of the commodity systems of $B$. rapa subsp. chinensis and S. retroflexum in Vhembe showed that production, transaction and consumption of the two vegetables are embedded in the food, trade and farming systems of local people. For both crops farmers had developed cultivation systems that appeared to be effective. They developed these systems by borrowing elements from the systems they used for the production of other crops to which they had added new knowledge specific to the crops concerned. This new knowledge had been acquired by means of on-farm experimentation and farmer-to-farmer knowledge exchanges and applied specifically to the collection of seed and the method of harvesting the leaves of the crops.

There were indications that agronomic research could bring about improvements to the existing systems. Specific elements of the production systems that could benefit from scientific enquiry were identified. These elements included genetic improvement of the crops, the effect of planting date on rate of development and yield for use in market planning and determining the water requirements of the two crops for optimum production. Using variability as an indicator of farmer uncertainty about what constituted best practice, nutrient supply was identified for both crops as one of the practices that needed research attention. The wide variability in nutrient application rates used by producers of both crops suggests that a significant proportion of farmers may be applying either too little or too much fertilisers for optimum production. Determining optimum planting density in $S$. retroflexum is another issue for research from which farmers are likely to benefit.

The local market for the two crops showed signs of expansion, but this did not prevent production from exceeding demand, particularly in the case of Chinese cabbage. Marketing of the two crops is primarily in the hands of petty traders who retail the crops in the streets of local towns. The high rate of migration of rural people to South Africa's metropolitan areas during the past two decades suggests the possibility of important but distant metropolitan markets for the two crops, but these still need to be explored.

The local way of preparing $S$. retroflexum involves the discarding of the first boiling water, a practice known to lessen the nutrient content of vegetables (Schippers, 2002). In the Eastern Cape, $S$. scabrum is boiled in combination with other leafy vegetables collected from the wild, including Sonchus asper, Chenopodium album and Amaranthus thunbergii. This reduces the bitter taste of the relish and obviates the need to discard the first boiling water (Siwundla, 2006). Similar approaches could be introduced in Vhembe to ensure that the nutrients contained in $S$. retroflexum are retained when the vegetable is prepared for consumption.

\section{Acknowledgement}

This article is based on work done in terms of a research project that is being supported financially by the Tshwane University of Technology, the South African Water Research Commission (WRC Project No. K5/1464//4 and WRC Project No. K5/1579//4) and the National Research Foundation (GUN2069585) but the authors accept full liability for any opinions, findings, conclusions or recommendations contained in this article.

\section{References}

DE LANGE M (1994) Small Scale Irrigation in South Africa. Water Research Commission, Rietfontein, Pretoria. 29 pp.

EDMONDS JM and CHWEYA JA (1997) Black nightshades: Solanum nigrum L. and related species: promoting the conservation and use of underutilised and neglected crops. IPGRI, Rome. [Online]. Available from: http://www.bioversityinternational.org/publications/ pufile.asp? pub=337 (Accessed on22/03/07).

GRABANDT K (1985) Weeds of Crops and Gardens in South Africa. Ciba-Geigy (Pty) Ltd, Johannesburg. 134 pp.

HILL DE (1990) Chinese cabbage and pak choi trials 1988-1989. Bulletin 879. The Connecticut Agricultural Experiment Station, New Haven. 11 pp.

HONG-FU Y (1988) The effect of nitrogen fertilizer application on the yield of Chinese cabbage. Asian Vegetable Research and Development Center Report [Online]. Available from: http://www.arc-avrdc. org/pdf files/Yanghongfu(6-N).pdf. (Accessed on 11/03/05).

JUMA KA (2006) Response of Solanum retroflexum Dun. to Nitrogen, Phosphorus and Potassium in Pots. M. Tech. (Agric.) Dissertation, Department of Crop Sciences, Tshwane University of Technology, Pretoria. 138 pp.

LEPLAIDEUR A (1994) Rencontre de la petite production marchande et du commerce informel des vivres en PVD: méthode d'analyse des rapports sociauxs. In: Benz $\mathrm{H}$, Lançon F, Leplaideur A, Moustier P and Pujo L (eds.) Méthodes d'Analyse des Rapports Sociaux Dans les Échanges Vivriers en Afrique et en Asie du Sud. Documents de travail du CIRAD-CA No 5-94. Centre de coopération internationale en recherche agronomique pour le developpement, Montpellier. 7-19.

LETSOALO SS and VAN AVERBEKE W (2006) Water management on a smallholder canal irrigation scheme in South Africa. In: Perret $\mathrm{S}$, Farolfi S and Hassan R (eds.) Water Governance for Sustainable Development: Approaches and Lessons from Developing Countries. Earthscan, London. 93-110.

MOUSTIER P, BERTON S and SECK PA (1997) Filières Maraîchères en Afrique: Guide Pratique d'Analyse. Rapport FAO/CGP/RAF/244 version provisoire. CIRAD, Montpellier. $105 \mathrm{pp}$.

OPEŇA RT, KUO CG and YOON JY (1988) Breeding and seed production of Chinese cabbage in the tropics and subtropics. Technical Bulletin No 17. Shanshua, Taiwan: Asian Vegetable Research and Development Center (AVRDC). 92 pp.

RUBATZKY VE and YAMAGUCHI M (1997) World Vegetables: Principles and Nutritive Values. ( $2^{\text {nd }}$ edn.) Chapman and Hall, New York. 843 pp.

SCHIPPERS RR (2002) African Indigenous Vegetables: An Overview of the Cultivated Species. Revised edition. [CD-ROM]. Natural Resources Institute/ACP-EU Technical Center for Agricultural and Rural Cooperation, Chatham. 252 pp.

STRYDOM H (2005) Sampling and sampling methods. In: De Vos AS, Strydom H, Fouché CB and Delport CSL (eds.) Research at Grass Roots (3 ${ }^{\text {rd }}$ edn.) Van Schaik, Pretoria. 192-204.

SIWUNDLA N (2006) Personal communication from Ms Nontsikelelo Siwundla who grew up on a farm near Debe Nek in the Eastern Cape. 27 August.

VAN AVERBEKE W and KHOSA TB (2004) The Triple-A framework for the analysis of smallholder food commodity chains. In: Proc. $3^{\text {rd }}$ Int. Conf. Entrepreneurship - Sustainable Globalization, 3-4 November, Pretoria. [CD-ROM]. Tshwane University of Technology, Pretoria, South Africa. 292-299. 
Available on website http://www.wrc.org.za ISSN 0378-4738 = Water SA Vol. 33 No. 3 (Special Edition) 2007 ISSN 1816-7950 = Water SA (on-line) 